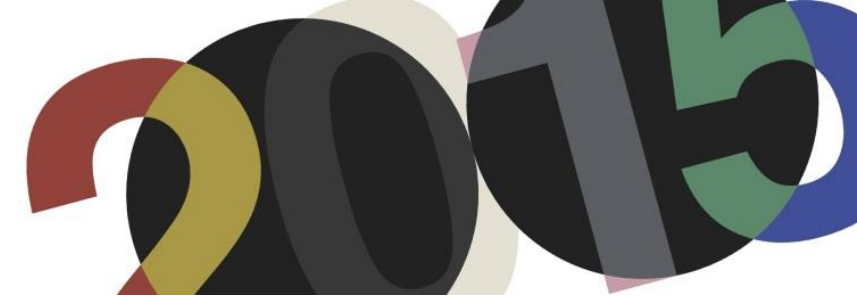

DOI: http://dx.doi.org/10.4995/LC2015.2015.1005

\title{
Maisons Jaoul, confort higrotérmico y su percepción en la arquitectura de tipología unifamiliar de Le Corbusier
}

\author{
D.V. Martín Fuentes \\ Escuela Superior de Arquitectura de Valencia
}

\begin{abstract}
Resumen: Se realiza un estudio completo, teórico, empírico, numérico y perceptual, de las Maisons Jaoul de Le Corbusier intentando esclarecer su comportamiento higrotérmico y climático. Con ello se pretende conocer en detalle la realidad de esta obra emblemática de la arquitectura doméstica del siglo XX. De la contraposición de los datos obtenidos en las dos viviendas de volumetría y compacidad prácticamente iguales, pero con una orientación ortogonal se extraen conclusiones reveladoras que no hacen más que afianzar la condición excepcional de las Maisons Jaoul dentro de la obra del arquitecto. Todo ello, tamizado por la percepción de los actuales habitantes de las viviendas.
\end{abstract}

Abstract: Trying to achieve a better understanding of the higrothermic performance of The Maisons Jaoul of Le Corbusier, they are studied from different approaches: theoretical, empiric, numeric and perceptual. The aim is to understand profoundly this emblematic building of the domestic architecture of the XX century. For that, the study analyses the project, but also compares and contrasts a series of data coming from the two houses which have a very similar volume and compactness but orthogonal orientation to finally take account of the perception of the actual inhabitants. Conclusions are revealing and strengthen the idea of how exceptional the Maisons Jaoul are in the architect's production.

Palabras calve: Le Corbusier; Maisons Jaoul; Confort higrotérmico; bioclimatismo, sostenibilidad. Keywords: Le Corbusier; Maisons Jaoul; Hygrothermal comfort; bioclimatic, sustainability.

\section{Introducción}

Los términos bioclimatismo, eco-eficiencia, sostenibilidad están actualmente muy en boga, más aún cuando la normativa al respecto del comportamiento energético es una realidad que un comportamiento responsable con nuestro entorno no puede obviar.

No podemos olvidarnos aun así que la arquitectura moderna y la arquitectura tradicional de todas las épocas ya han tratado y resuelto ampliamente esta temática. Para no incurrir en los errores cometidos en el pasado hacemos un repaso de las herramientas bioclimáticas de la arquitectura de uno de los maestros del s. XX, Le Corbusier, concretando el análisis en dos de las viviendas de su época madura, las Maisons Jaoul.

\section{Metodología}

En el estudio se plantea el análisis de las Maisons Jaoul desde tres puntos de vista que se suplementan y permiten obtener conclusiones globales: el teórico, el empírico y el perceptual.

Inicialmente se realiza un análisis teórico que se aborda desde dos vertientes completamente distintas. Primero el desarrollo contextual e histórico donde se analizan las herramientas bioclimáticas de Le Corbusier y su aplicación específica en las viviendas. Segundo el numérico realizando un modelizado en base al que se obtienen parámetros de comportamiento térmico, lumínico y de confort higrotérmico. 
Posteriormente el análisis es numérico también, pero empírico. Se realiza un comparativo con los datos obtenidos en una monitorización in situ en Enero de 2015.

Finalmente estos datos se modulan con la opinión de los habitantes actuales de las viviendas y su percepción de la adecuación térmica, lumínica y de confort general. Con todo ello se emiten las conclusiones globales que no hacen más que afianzar la condición excepcional de las Maisons Jaoul dentro de la obra de Le Corbusier.

\section{Le Corbusier bioclimático. Machine à habiter vs Coquille de l'escargot}

Desde el inicio de su carrera, Le Corbusier afronta la adaptación climática del edificio, entendida esta como el confort higrotérmico de sus ocupantes, como un requerimiento programático más. En coherencia con su actitud investigadora, pionera y sistemática, veremos cómo adopta diferentes soluciones a lo largo de su obra, no siempre con la efectividad deseada, pero siempre conceptualmente reveladoras.

Como gran maestro, aprende en cada situación y es capaz de evolucionar. Desde las viviendas que se diseñan como machine à habiter -en las décadas de 1920 y 1930 - hasta las viviendas que concibe para la India o las Maisons Jaoul, con un concepto mucho más íntimo; hay un gran salto que se recorre paso a paso. Aun así no podemos olvidar que Le Corbusier ya decía en 1926: "For mi the house is more tan a machine à habiter; it is also la coquille de l'escargot." ${ }^{11}$ No se puede negar que era consciente de la necesidad de protección y confort que una vivienda debe satisfacer a sus usuarios pero es posible que tal y como indica Caroline Maniaque:

"Witold Rybczynski ha estudiado la historia del confort desde la edad media hasta nuestros días. [...] Para él los arquitectos estaban demasiado centrados en responder visualmente a la estética de la era industrial en vez de al bien estar de los ocupantes."2

Respecto a los proyectos de la era maquinista, lo más significativo, en términos de control higrotérmico, es su confianza en la utilización de ciertos sistemas muy novedosos. Se concentra en inventar el mur neutralisant y utilizar sistemas que permitan una respiration exacte. Más que una respuesta estructural, propone soluciones mecánicas, intentando crear edificios isothermiques eficaces contra el frío y el calor.

"propongo técnicas científicas internacionales: una sola casa para todos los países, todos los climas: la vivienda con respiración exacta”.

El mur neutralisant es un sistema de atemperamiento del interior del edificio consistente en la impulsión de aire seco en el interior de la cámara estanca del doble acristalamiento de los paños de vidrio -aunque también en el resto de cerramientos. Este aire se climatizaría: frío, en verano, y caliente, en invierno; mediante intercambiadores de calor. Para la ventilación mecánica, idea L'aireation ponctuelle, que consistía en la impulsión de aire puro a $18^{\mathrm{a}} \mathrm{C}$ con recuperación dentro de circuito cerrado.

\footnotetext{
${ }^{1}$ Le Corbusier, L'Almanach d'Architecture moderne (Paris: Crès, 1926; Paris: Connivence, 1975), 5

${ }^{2}$ Maniaque Benton, Caroline: Le Corbusier and the Maisons Jaoul. New York: Princeton Architectural Press, 2009. p. 109.

${ }^{3}$ Boesiger, Willy (Ed.) ; Le Corbusier ; Stonorov, O: Le Corbusier et Pierre Jeanneret. Oeuvre complète 1910-29. Zurich: Les Éditions d'Architecture, 1973. p. 210.
} 
El mismo Le Corbusier afirmaba que "los primeros efectos de la revolución industrial en la construcción se manifiestan mediante esta etapa primordial: el reemplazo de los materiales naturales por los materiales artificiales, de los materiales heterogéneos y dudosos por los materiales homogéneos y probados con ensayos de laboratorio y producidos con elementos fijos. El material fijo debe reemplazar el material natural, variable hasta el infinito"4. Expresaba su confianza en las tecnologías ya que "en todos los dominios de la industria, se han planteado problemas nuevos, y se han creado las herramientas capaces de resolverlos."

Pero es en ciertos proyectos de vivienda donde debido a los condicionantes climáticos, de presupuesto, de lejanía o por el propio cliente, en los que aparece de una manera más evidente un cierto cambio de actitud. "Los problemas de sobrecalentamiento conducen a Le Corbusier a buscar métodos de naturaleza completamente arquitectónica para controlar las sombras sobre el paño de vidrio; es así que nace el dispositivo de brise-soleil."6

Tim Benton analiza y desarrolla en su artículo "La Villa Baizeau et le brise-soleil” cómo para Le Corbusier "este proyecto debe demostrar la capacidad de su arquitectura para resolver todos los problemas naturalmente."7

En el invierno de 1927-28, Lucien Baizeau, un industrial tunecino, le encarga a Le Corbusier el diseño de una pequeña casa en Sainte-Monique, Túnez. Hasta el momento el arquitecto no tiene ninguna experiencia en construcciones adaptadas a climas calurosos. En este caso, es el cliente el que insiste en la necesidad de que la vivienda necesita una protección directa del sol y de los vientos calientes de Sur y Suroeste; así mismo indica que la ventilación interior debe ser "perfecta".

Lejos de limitar los resultados, Le Corbusier propone nuevas soluciones. En este proyecto aparecen los característicos plan libre y façade libre, una sugerente sección en doble U entrelazada que establece una coupe libre (sección libre), también se plantea el "techo-parasol”, que asegura una protección solar.

Finalmente, algunos de estos elementos desaparecen del proyecto y el sistema utilizado -fuertemente entroncado con el sistema domino- representará posteriormente un arquetipo en el diseño de viviendas y "se convertirá en una fuente de inspiración para el brise-soleil no sin haber influenciado fuertemente el primer proyecto de la Ville Savoye (Octubre 1928)."9

Dos años después, en 1930, es en el proyecto de la casa Errazuris en Chile donde se hace indiscutible la aparición de un nuevo universo material en su arquitectura. El cambio de imagen es explicado en la Oeuvre Complète por la inexistencia de una mano de obra técnica suficiente, la utilización de materiales del lugar y una colocación en obra fácil.

Los muros de piedra que hasta entonces no había utilizado atestiguan que "la confrontación entre la tecnología moderna y la materia desnuda y ruda realizada con técnicas ancestrales constituye entonces un descubrimiento plástico de primer orden. Además, también parece simbolizar que no es posible encontrar una arquitectura

\footnotetext{
${ }^{4}$ Le Corbusier: Vers une architecture. Paris: Vincent, Freal and Cie., 1958. p. 192. (Libro editado por primera vez en 1923)

${ }^{5}$ Ibidem. p. 228.

${ }^{6}$ Siret, Daniel ; Harzallah, Amina: Architecture et côntrole de l'ensoleillment. Conferencia, manuscrito publicado en "Congrès IBPSA France", Ecole national Supérieure d'Architecture de Nantes, France 2006.

${ }^{7}$ Benton, Tim: "La Villa Baizeau et le brise-soleil", A.A.V.V. Le Corbusier et la Mediterranée. Marseille : Editions Parenthèses, 1987. pp. 125-129.

${ }^{8}$ Este hecho es importante puesto que en Marzo de 1951, justo cuando recibe el encargo de la Villa Shodhan (India), Le Corbusier hace explícita referencia al "techo para Baizeau, Túnez" en uno de sus Carnets, 25 años después.

${ }^{9}$ Ibidem. p. 127
} 
francamente moderna si no existe una verdadera conciencia de la cultura y la tradición. ${ }^{, 10}$ En la siguiente década construye y proyecta diferentes viviendas de estas características.

La Villa de Mme. Mandrot (1931) en Le Pradet, Francia, ilustra el uso de paredes de piedra sin revestir dentro de una sintaxis siempre moderna. La planta es libre y esto permite la existencia de grandes paños de vidrio, que en bastantes casos se sustituyen por láminas opacas o paneles contrachapados para atenuar el calor y la intensidad lumínica. Estos entrepaños presentan un diseño de cuidada geometría que recuerda a las composiciones pictóricas neoplasticistas.

Las mismas características presenta la Villa en los Mathes (1935). El cliente, Albyn Meyron, escribe a Le Corbusier indicando que no desea "una construcción ligera, industrial, perecedera y que exija gastos de mantenimiento. Confiesa su desconfianza en los prototipos industriales y su aspecto exterior de bains parisiens" $"$. La casa resulta entrar en armonía con el entorno, se cierra bien en inverno, resiste el salitre del ambiente y las lluvias de otoño, pero no necesita mimetizar imágenes, ni lenguajes, ni siquiera materiales, únicamente sistemas y disposiciones. La distancia con el regionalismo típico de otras arquitecturas del momento es patente, de hecho no existe reminiscencia alguna de una determinada tradición estilística.

En la Villa Henfel (1934-35) denominada maison de week-end y construida en las afueras de París, el diseño está encaminado a satisfacer un "principio impuesto": la casa debe ser lo menos visible posible, tal y como se recoge en la Oeuvre Complète. Para ello se implementan recursos que en otros casos se habían justificado por la lejanía e imposibilidad de controlar la obra, pero que en realidad parecen responder a una sensibilidad con el entorno: "...techo de hierba sobre bóvedas rebajadas, elección de un material tradicional, la sillería con aparejo en seco." ${ }^{12}$ Destaca el orden de descripción del techo, parece ser más importante la hierba que la propia cubrición.

Presentan continuidad con la nueva actitud la casa Locheur (1929), prototipo de vivienda estandarizada y taylorizada pero con los nuevos materiales; la casa del Dr. Rameaux (1936), las "Maison pour ingénieurs et contremâitres Lannemezan" (1940) y las casas Murondins (1940).

Según varios autores, el proyecto para las casas Locheur en Francia y la casa para Errazuris, suponen en la práctica el fin del sueño de crear la casa taylorizada. Si en las casas Loucheur Le Corbusier asume que la mitad del mercado inmobiliario francés está formado por "innumerables pequeños propietarios $[\ldots]$ y las circunstancias actuales hacen absolutamente imposible de realizar la construcción de una casa en las condiciones técnicas suficientes y en buen precio"13, en la casa de Chile adapta sus ambiciones tecnológicas a la disponibilidad del lugar. El fracaso de este proyecto de taylorización, así lo califica Kenneth Frampton, conduce a una apuesta por "las tecnologías intermedias que combinan técnicas primitivas y punteras según las necesidades y los medios"14.

El viaje que realizó en 1931 a Marruecos y Argelia, le permitió certificar la estrecha relación entre arquitectura, cultura, paisaje y hombre. No hay duda de que quedó influenciado por la intrínseca racionalidad que la arquitectura popular presenta cuando se trata de integrarse en la naturaleza y protegerse de ella.

\footnotetext{
${ }^{10}$ Torres Cueco, Jorge: Le Corbusier: Visiones de la técnica en 5 tiempo. Barcelona: Colección Arquithemas, 2004. p. 151

${ }^{11}$ Carta mecanografiada del 12 de Diciembre de 1934. FLC H-2-9, piezas 161-163. Extraída de Torres Cueco, Jorge: Le Corbusier: Visiones de la técnica en 5 tiempo. Barcelona: Colección Arquithemas, 2004.

${ }^{12}$ Bill, Max (Pub.); Le Corbusier: Le Corbusier. Oeuvre complète 1934-38. Zurich: Les Éditions d'Architecture, 1973. p. 125 .

${ }^{13}$ Boesiger, Willy (Ed.) ; Le Corbusier ; Stonorov, O: Le Corbusier et Pierre Jeanneret. Oeuvre complète 1910-29. Zurich: Les Éditions d'Architecture, 1973. p. 78.

${ }^{14}$ Frampton, Keneth: Le Corbusier. Turín, Ediciones Hazan, 1997
} 
Paradójicamente en estos mismos años está desarrollando parte de sus "grandes construcciones" donde aborda, como ya hemos visto, el confort desde una perspectiva muy distinta. En definitiva, las circunstancias en unos proyectos y otros son difícilmente asemejables, pero se puede comprobar que lo ocurrido en estos años abre para Le Corbusier una nueva vía de investigación, encabezada por el brise-soleil, que generará múltiples herramientas [bio]climáticas que se aplicarán en todos sus proyectos -independientemente de la escala- a partir de la década de los años 30 y significativamente después de la guerra.

La máquina como modelo de precisión y progreso universal es desplazada por una relación más cercana con la naturaleza, el lugar, el clima, y una valoración cercana de las culturas vernáculas, que tan bien han funcionado.

"He has an attitude to technology. There is a sense of passion for nature that motivated a very deep desire to find functional solutions that would allow, for instance, the free passage of light, air and control of the sun's energy.",15

\subsection{Herramientas bioclimáticas}

Los problemas de sobrecalentamiento conducen a Le Corbusier a buscar métodos de naturaleza completamente arquitectónica para controlar las sombras sobre el paño de vidrio, es así que nace el dispositivo de brise-soleil, pero no es el único. A lo largo de su obra va desarrollando, en unas ocasiones de manera intuitiva, en otras tras un proceso de profundo análisis otras herramientas enteramente proyectuales que le permiten mejorar el confort higrotérmico de sus edificios.

A las protecciones solares y la orientación, añade otros parámetros indispensables para entender sus construcciones de la década de los 50. En la época en la que diseña las Maisons Jaoul, los materiales que utiliza aportan mayores inercias térmicas, los muros y las ventanas adquieren profundidad (espesor); las cubiertas se ajardinan o doblan y las corrientes de aire se tienen en cuenta.

Se puede de manera sintética enunciar las herramientas que conducen la arquitectura de Le Corbusier hacia un mayor control climático, lo que se traduce en mayor sostenibilidad, y en base a ellas analizaremos las Maisons Jaoul: Orientación, Brise-soleil, Cubierta ajardinada o doble, Materialidad, Cerramientos practicables (ventanas) y Circulación de Aire.

\section{Estudio Teórico. Maisons Jaoul: Brutalismo domesticado}

En Le Corbusier and The Maisons Jaoul, Caroline Maniaque describe de manera extensa y detallada la relación de amistad existente entre el arquitecto y la familia Jaoul. Por fases se analiza el proceso de diseño que concluyó en la solución definitiva de las viviendas.

En 1946, los Jaoul -Michel y su hijo André- compraron un solar en Neully-sur-Seine población cercana a París en la que pretendían instalarse ese mismo año. Dado el poco tiempo del que disponían y que necesitaban resolver el problema de alojamiento inmediatamente incluso estaban dispuestos a vivir en un chalet de madera tipo

\footnotetext{
${ }^{15}$ Menin, Sarah; Samuel, Flora: Nature and Space, Aalto and Le Corbusier. Londres, Ed. Route Ledge, 2003, p. 2.
} 
australiano. Como en esa época Le Corbusier estaba inmerso en muchos de sus grandes proyectos ${ }^{16}$ les puso en contacto con un arquitecto inglés, Clive Entwistle ${ }^{17}$, para que diseñara y construyera su vivienda.

En Junio de 1951, Entwistle dibujo una propuesta que constaba de un bloque de PB+III con las viviendas superpuestas. Su propuesta mezclaba motivos formales de imagen corbuseriana y una estructura modular muy racional, típica de las propuestas de arquitectos ingleses en aquella época. Ese mismo año, en un encuentro durante uno de sus viajes a Nueva York, Michel Jaoul pidió a Le Corbusier que echara un vistazo a los planos y este los criticó, especialmente la superposición de las viviendas. Utilizaba como argumento principal que los materiales bastos y sin necesidad de acabados especiales, además de ser más acordes con la estética que propugnaba por ese entonces permitían un ahorro del $20 \%$.

En definitiva acabó aceptando el encargo del diseño y le dedicó, entre la vorágine de las grandes construcciones una atención y cuidado acordes con la relación amistosa e intelectual que le unía con la familia.

Centrando el análisis en las herramientas bioclimáticas anteriormente reseñadas podemos entender muchas de las decisiones proyectuales que se tomaron. Obviamente las Maison Jaoul son mucho más que lo que aquí se analiza pero merece la pena centrar la atención en estos parámetros para entender el nivel de madurez alcanzado por Le Corbusier en las cuestiones que nos incumben. ${ }^{18}$

\subsection{Orientación}

En 1951, se establece el plan de ordenación de Neully-sur-Seine bajo el que se rigen todas las nuevas construcciones del distrito. La calle de Longchamp, en la que se sitúa el solar adquirido por la familia Jaoul, estaba afectada por un número de plantas de PB+3 y una altura de cornisa de $12 \mathrm{~m}$. Con un coeficiente de edificabilidad de 1.30, la ocupación en planta tenía que ser como máximo de $32 \%$ y adicionalmente se establecía un retranqueo obligatorio del vial de al menos $4 \mathrm{~m}$.

Todos estos condicionantes, junto con el edificio que existía adosado al linde suroeste, hacen que la labor de buscar una buena orientación para las viviendas quede prácticamente relegada a un segundo plano, dando prioridad a un posicionamiento de los volúmenes construidos con criterios principalmente programáticos. A pesar de ello, en la primera visita al lugar Le Corbusier tomó ciertas notas en su cuaderno sobre los ángulos de incidencia solar que dictarían la configuración. Analizó el espacio, su exposición, orientación y las posibilidades de control de la luz antes de desarrollar cualquier idea preliminar. ${ }^{19}$

El obstáculo principal consistía en un edificio de ladrillo de cuatro alturas que está - sigue construido-separado $7.5 \mathrm{~m}$ de la calle. Le Corbusier dibuja el perfil de la medianera desnuda y el sol de la mañana y la tarde asomando a los lados. La utilización de la trayectoria solar como estrategia de diseño sigue siendo a pesar de las dificultades presentes como un acto de fe en el sol.

En otra hoja de ese mismo cuaderno también dibuja el resto de perfiles de cada lado del solar y apunta los inconvenientes "sombra (agujero bastante oscuro) y ruido proveniente de la calle. [...] El esfuerzo destacable

\footnotetext{
${ }^{16}$ La Unité d’Habitation de Marsella (1945-52), todo el diseño de grandes edificios de la India en Ahmedabad y Chadigarh, los proyectos de urbanismo de ese país, el diseño de Bogotá; son proyectos que desarrollaba entonces. Incluso durante 1951 diseñó y pintó las ilustraciones de su manuscrito Le Poème de l'angle droit, que fue publicado finalmente en 1955.

${ }^{17}$ Le Corbusier lo conocía porque se había puesto en contacto con él para traducir el libro Propos d'urbanisme.

${ }^{18}$ No se realiza análisis de la herramienta brise-soleil puesto que no se utilizó como tal en las Maisons Jaoul.

${ }^{19}$ Maniaque Benton, Caroline: Le Corbusier and the Maisons Jaoul. New York: Princeton Architectural Press, 2009. p. 45.
} 
que puso en la elaboración de estos bocetos iniciales claramente muestra su atención a los factores solares para conseguir maximizar su influencia en el diseño inicial." ${ }^{20}$

Finalmente, las viviendas se dispusieron en dos lados ortogonales del patio privado, haciendo que tengan orientaciones distintas. En muchas de las versiones que se realizaron, las viviendas tienen un posicionamiento paralelo, pero finalmente tal y como comentábamos tuvo mayor peso una correcta ocupación del espacio existente.

\subsection{Cubierta ajardinada}

La cubierta ajardinada se da en gran cantidad de proyectos de Le Corbusier. Fue formulada muy pronto y respondía más a ideas proyectuales abstractas que a una búsqueda específica de soluciones bioclimáticas. Tan importante era este concepto que lo incluyó en los "cinco puntos" de la arquitectura.

En principio se justificaba como devolución a la "naturaleza" del terreno ocupado por la casa, favoreciendo el disfrute de un jardín privado, pero el mismo Le Corbusier era consciente del papel que jugaba para alcanzar el confort interior. Su capacidad aislante protegía las nuevas cubiertas de hormigón armado plano de los cambios de temperatura exterior. También los planteó como solución para reducir las necesidades de calefacción en los espacios interiores. Adicionalmente la cubierta plana -que facilita el ajardinamiento- posibilita la colocación de las bajantes en el interior de la vivienda y al estar el interior calefactado se evitaba que estas se congelaran con los problemas que esto conlleva.

En 1927 Le Corbusier publicó en la revista L'Architecture Vivante "La teoría de la cubierta Jardín" un documento que trata de la planeación y el uso de la terraza. En él defiende su uso extensivo para todo tipo de climatologías. "Se puede admitir que igualmente es aplicable a los casos medios (climas templados, suaves, o incluso cálidos). El hormigón armado es el nuevo medio que permite la realización de una cubierta homogénea [...]. En Conclusión: razones de orden técnico, económico, de confort e incluso sentimentales nos lleva a adoptar como solución la cubierta terraza". ${ }^{21}$

Obras en localizaciones tan distintas como la villa Le Lac que hizo para su madre frente al lago Le Mans, la villa Henfel (casa para fin de semana) o la villa Sarabhai son testimonio de aquello en lo que Le Corbusier tanto insistió años más tarde: la conjunción entre el soporte de hormigón armado, la impermeabilización flexible y el remate mediante una capa vegetal es una de las soluciones constructivas más acertadas y duraderas que se pueden realizar.

Lo cierto es que la utilización de cubiertas ajardinadas ha tenido gran proyección histórica de manera destacable en la época actual, habiendo generado un curioso concepto comercial, las cubiertas ecológicas, en el marco de la denominada "naturación urbana". Las cubiertas vegetales suponen una herramienta bioclimática de primer orden por la cantidad de ventajas que tienen. No sólo a nivel higrotérmico sino acústico, de contaminación y de absorción de $\mathrm{CO}^{2}$.

En las Maisons Jaoul se incluyeron desde los primeros bocetos, y a pesar de tener un espesor variable debido a la estructura horizontal de bóveda catalana, funcionan como un buen aislante.

\footnotetext{
${ }^{20}$ Ibidem. P.46

${ }^{21}$ Le Corbusier: "Théorie du toit-jardin", en L'Architecture vivante, Otoño-Invierno, 1927. Paris: Jean Badovici. pp. 13-18.
} 


\subsection{Materialidad}

“En la década siguiente (1950-60)... El mundo de la arquitectura anhelaba su trabajo, temblaba y obedecía. [...] De las casas Jaoul, Stirling y Gowan inteligentemente aprendieron un nuevo camino en la arquitectura doméstica (y el resto del mundo aprendió de ellos)" 22

Las Jaoul son una de las obras que mejor representa esa utilización de materiales más elementales que hemos comentado. Las viviendas están construidas con ladrillo, hormigón, rasillas planas, bóvedas "a la catalana", cubiertas revestidas de hierba.

Cabe destacar que, aunque realmente no es una obra rompedora sino que se encuadra en una línea evolutiva lógica que comenzó en la década de 1930, sí que tuvo mucha repercusión en los arquitectos coetáneos, muchos de los cuales evolucionaron hacia una corriente postmoderna. Probablemente esto ocurrió así porque su dimensión es superior a otras viviendas anteriores, por la complejidad del programa fantásticamente resuelto y por su localización muy cercana a les Champs Elysées en Paris, en Nuilly-sur-Seine.

"No hay referencia alguna a ningún aspecto mecánico en Jaoul, ni en construcción ni en estética. Estas casas que en total costaron 30.000 libras esterlinas, fueron construidas por obreros argelinos equipados con escaleras, martillos y clavos, y, a excepción del vidrio, no se utilizó ningún material sintético; tecnológicamente no suponen ningún avance con respecto a la construcción medieval. ${ }^{, 23}$ Pero destilan modernidad en todos los aspectos.

El nuevo repertorio de materiales: hormigón, ladrillo, madera, tierra y pétreos es sostenible económica, térmica y naturalmente hablando. Son baratos por su abundancia, facilidad de obtención y en general cercanía entre el lugar de producción y de colocación (se reducen los transportes). Además debido a su buen comportamiento térmico reducen el consumo en acondicionamiento interior. Al menos en ese momento eran aislantes con mejor comportamiento que los industrializados y con una inercia térmica muy superior. Al ser productos naturales o con un reducido proceso de fabricación suponen una menor emisión de $\mathrm{CO}^{2}$ a la atmósfera (han sido generados de manera natural por el propio planeta), en muchos casos su reutilización es factible, su mantenimiento y reciclaje es sencillo y en cualquier caso, debido a su composición, son biodegradables.

Aunque es cierto que de este grupo de materiales de construcción se tiende a excluir al hormigón y a los cerámicos (ladrillo), las nuevas técnicas de trituración y molido para generar áridos para nuevos hormigones y rellenos los acercan al grupo de materiales con un reducido impacto negativo sobre el medioambiente por su capacidad de reciclaje.

En estas viviendas, fundamentalmente cuando la composición en planta responde a un sistema de naves concatenadas, los muros son portantes y por tanto su espesor es mayor de lo que había sido en los cerramientos de las viviendas puristas. Los límites de mayor espesor y mayor inercia mejoran el comportamiento térmico y acústico de los paramentos que están "revestidos por el interior (enyesados) para evitar las condensaciones."24

\footnotetext{
${ }^{22}$ Banham, Reyner: Le Corbusier: "A critique of his work", The Architectural Review. Octubre 1966, no 834. pp. 97-108.

${ }^{23}$ Stirling, James: "De Garches a Jaoul. Le Corbusier como arquitecto doméstico en 1927 y 1953". Anales de Arquitectura. 1993, $\mathrm{n}^{\circ}$ 5. Valladolid: Universidad de Valladolid. pp. 209-213. Artículo recogido y traducido, original: "From Garches to Jaoul: Le Corbusier as Domestic Architect in 1927 and 1953". The Architectural Review. Agosto 1955, n 118.

${ }^{24}$ W. Boesiguer y G. Girsberger: Le Corbusier 1910-1965, Barcelona, Editorial Gustavo Gili, 1971.
} 
Y a la vez que los cerramientos opacos adquieren espesor, los entrepaños o cerramientos semitransparentes ganan profundidad y se concreta "La "cuarta pared" -la incorporación de estantes y materiales opacos dentro de las ventanas- (que) es sintomática de la reciente actitud de Le Corbusier ante la profundidad de la superficie. Las ventanas no existen ya para mirar a través de ellas, sino para ser contempladas." ${ }^{25}$

\subsection{Cerramientos practicables (ventanas)}

Conjuntamente con la nueva materialidad, y a pesar de que esta pueda ser relacionada con una vuelta a los orígenes, la concepción moderna de la ventana como un desencuentro entre dos muros, en el proyecto de las Jaoul se potencia. Los entrepaños que cierran el espacio de muro a muro se construyen en madera -material de altas prestaciones- y se componen de entramados o mallas de cuidada composición que disocian "huecos" de diferente función. Unos son transparentes -aunque no necesariamente practicables- para la iluminación; otros son practicables -aunque no necesariamente transparentes- para la ventilación; otros albergan estantes, incluso muebles cerrados y otros son simplemente opacos.

La madera es un material con muy reducida huella ecológica (si su producción es en bosques responsables) y es un magnifico aislante térmico. Construyendo los huecos a la manera de la "cuarta pared" se minimizan los puentes térmicos en el punto más delicado de la envolvente térmica.

Son ejemplos de esta magistral aplicación de la "ventana" las viviendas trabajadas en la misma línea que la casa Errazuriz posteriormente a 1930. Y a pesar de que al principio es menos obvio, a partir de los tipos de casas S.P.A. Lannemezan para "contremâitre" et ingenieur", 1940, la "cuarta pared" se utiliza explotando al completo sus posibilidades, ya que contiene (en este proyecto en concreto) todos los muebles de las habitaciones a excepción de la cama (mesitas, estantes y pupitres).

El término "cuarta pared" aparece en "Problemes de l'ensoleillement" inicia con los estudios teóricos para el rascacielos del Barrio de la Marina en Alger (1938-42) y se basa en la aplicación de la "fachada libre". En la Oeuvre complète Le Corbusier señala las ventajas del brise-soleil para el interior de las oficinas cuando éste se agranda y convierte en loggia. Añade además de las bondades de la protección solar, la posibilidad de limpiar el vidrio desde el exterior porque está al alcance de la mano y resalta sobre este cerramiento que su "diseño presenta la posibilidad de una diversidad considerable."27

En el mismo texto el arquitecto explica "...[al brise-soleil] se le añadirá el "brise-vent" con la posibilidad de constituir paredes herméticas acristaladas traslúcidas, transparentes, opacas si queremos. Se alcanza una conquista arquitectónica: la explotación de la cuarta pared de la habitación."28,

Y tal y como se observa en el esquema que acompaña al escrito en la Oeuvre Complete, al igual que en función de la altura se desplaza la posición del paño -para corregir la escala de la protección solar- se puede ajustar su diseño y equipamiento al uso de la estancia que sirve. El entramado admite contener paneles fijos o abatibles, traslúcidos o trasparentes, de vidrio normal o helado, pavés. Incluso se le pueden añadir muebles, cajoneras,

\footnotetext{
${ }^{25}$ Ibidem. Stirling, James.

${ }^{26}$ Boesiger, Willy; Le Corbusier: Le Corbusier. Oeuvre complète 1938-46. Zurich: Les Éditions d'Architecture, 1973. pp. 103-115.

${ }^{27}$ Ibidem, p. 106.

${ }^{28}$ Ibidem, p. 107.
} 
baldas o paneles decorados. El sistema también permite controlar la entrada de luz en la estancia deslizando pantallas correderas unas sobre otras para tamizar al 30\%, 60\% o 100\% las superficies acristaladas.

\subsection{Circulación de Aire}

La introducción en el proyecto arquitectónico de las correcciones climáticas a través del viento y la brisa no resulta sencilla, existiendo una elevada imprecisión en su diseño. "La norma general debe consistir en prever sistemas flexibles y confiar en que los usuarios sepan utilizarlos con la máxima eficacia". ${ }^{29}$ Existen muchas posibilidades como chimeneas solares, aspiradores estáticos, torres solares pero el más sencillo y eficaz es la ventilación cruzada. Ésta se mejora si se produce a través de un patio, por la capacidad que tiene de crear un microclima específico y de actuar como filtro entre las condiciones exteriores y las interiores.

Tal vez el binomio de ventilación cruzada-doble orientación es uno de los que menor desarrollo alcanza en los procesos teóricos de Le Corbusier en un modo perceptible, pero desde luego marca todo su trabajo profundamente desde el inicio y en realidad es generador de preceptos básicos en su lenguaje estilístico y compositivo, especialmente en la década de los 50. Todos sus edificios de esta década, a partir de la experiencia en la India están dotados de aerateurs y las Maisons Jaoul no son una excepción.

Una de las primeras viviendas en las que experimenta con este efecto es la casa Curruchet (1949), vivienda unifamiliar entre medianeras en la ciudad de La Plata, que contiene un patio central encerrado entre dos grandes volúmenes y "situado hacia el medio del lote que actuaría como una suerte de 'chimenea' natural de extracción del aire caliente proveniente de las estancias inferiores" ${ }^{\prime 30}$.

Las viviendas de Neuilly-sur-Seine tienen, tal como indicábamos en el apartado anterior, un diseño de huecos que disocia las funciones de manera que existen huecos que son específicos para ventilar. En la figura 1 podemos ver un esquema teórico de las ventilaciones cruzadas que se generarían con la apertura de estos huecos.

\footnotetext{
${ }^{29}$ Serra, Rafael Serra: Arquitectura y Climas. Barcelona, Gustavo Gili, 1999. p. 57.

${ }^{30}$ Gómez Sierra, Carlos M.: "Le Corbusier y la casa Curruchet. Una aproximación teórica desde la problemática del clima", Área digital. "Área historia. Utopía y ciudad". Febrero 2002 nº 2. Chaco, Argentina. Facultad de Arquitectura y Urbanismo.
} 

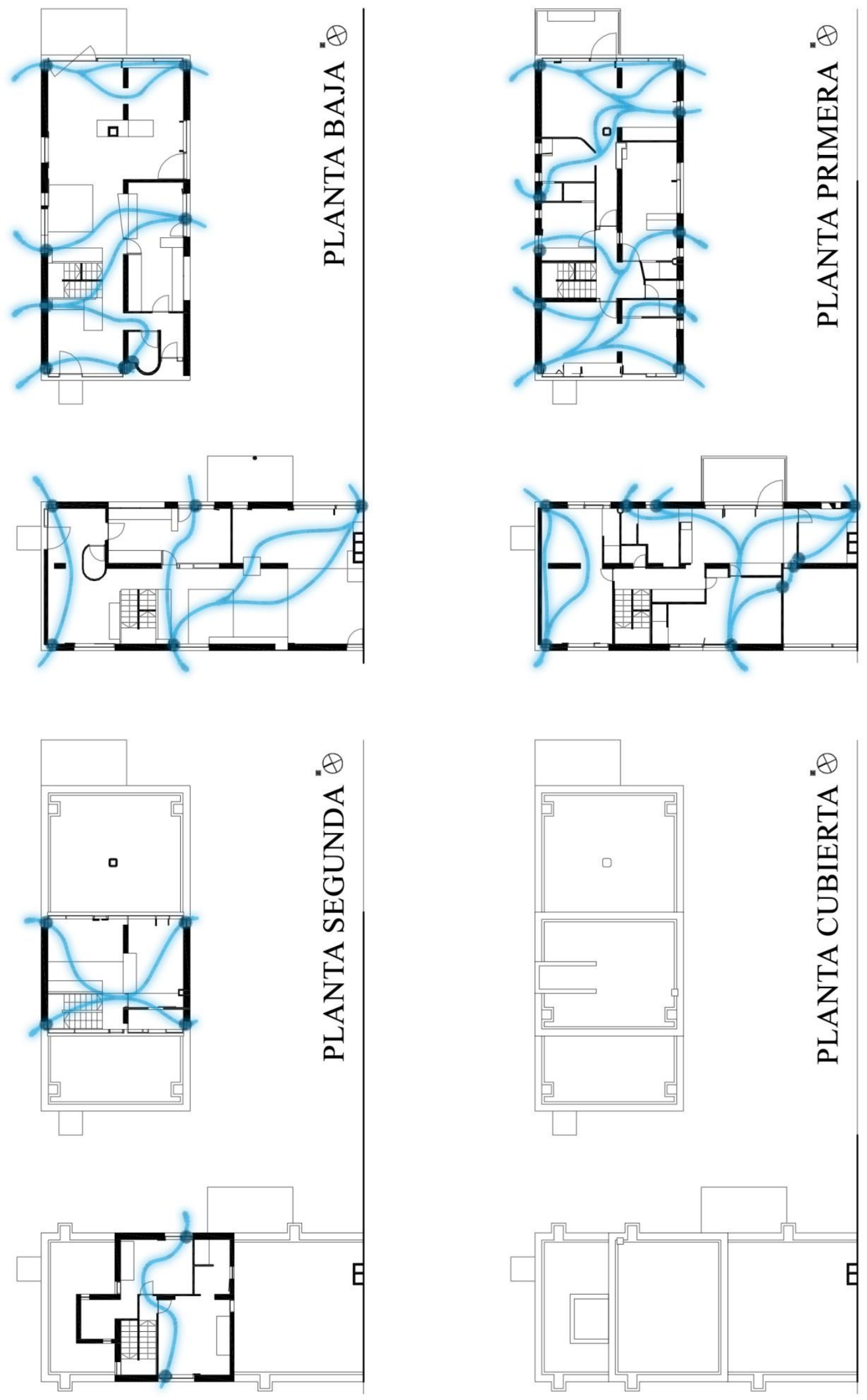

1. Esquema de ventilaciones cruzadas establecidas exclusivamente mediante aerateurs. 
Las estancias que recaen en las fachadas de menor longitud son espacios únicos, así se facilita una buena ventilación cruzada de manera directa. Por el contrario, el resto de estancias dependen de tener las puertas abiertas para que la ventilación se produzca efectivamente. Este hecho que puede resultar incómodo en un edificio público, en una vivienda es bastante factible, al menos durante gran parte de la jornada. Si bien es cierto, algunos trazados de corrientes son muy intrincados y es difícil que se produzcan en momentos en los que no haya viento simplemente por gradiente de temperaturas entre fachadas.

\section{Estudio teórico.}

Los parámetros que influyen en el comportamiento higrotérmico de un edificio son múltiples. Las instalaciones adquieren relevancia en el comportamiento global puesto que pueden corregir en cierta medida los resultados de un diseño poco cuidado -a costa de consumo energético-, pero por el contrario, pueden generar humedades o acrecentar problemas de confort interior. A pesar de todo ello, el comportamiento global depende en mayor medida sobre el diseño arquitectónico y especialmente de la envolvente frente a las condiciones de contorno.

\subsection{Modelizado}

A través de Ecotec Analysis 2011 de Autodesk se han estudiado las viviendas. El modelizado ha permitido obtener datos de la incidencia solar sobre las viviendas y de las sombras que generan pero también el entorno construido y vegetal.

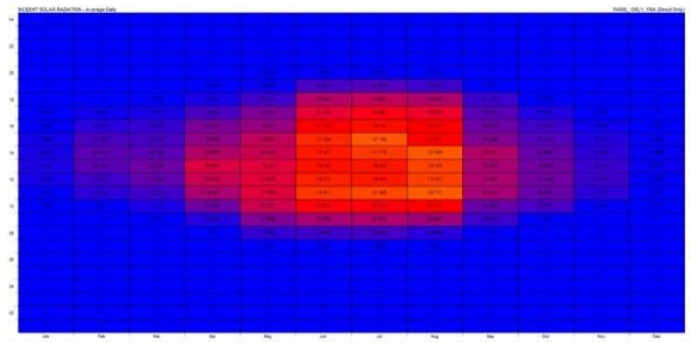

Vivienda A

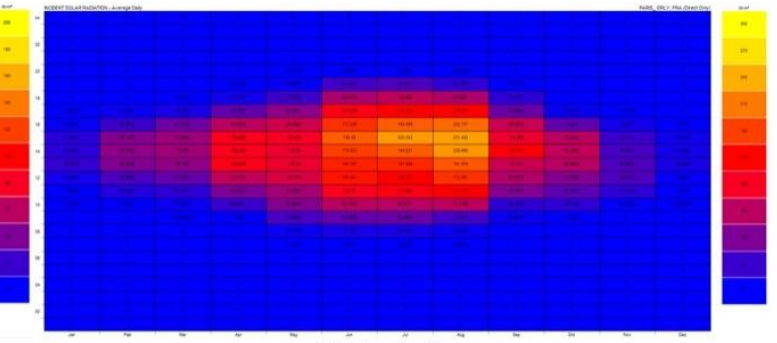

Vivienda B

2. Gráfico comparativo. Radiación Solar Directa y Difusa en las dos viviendas.
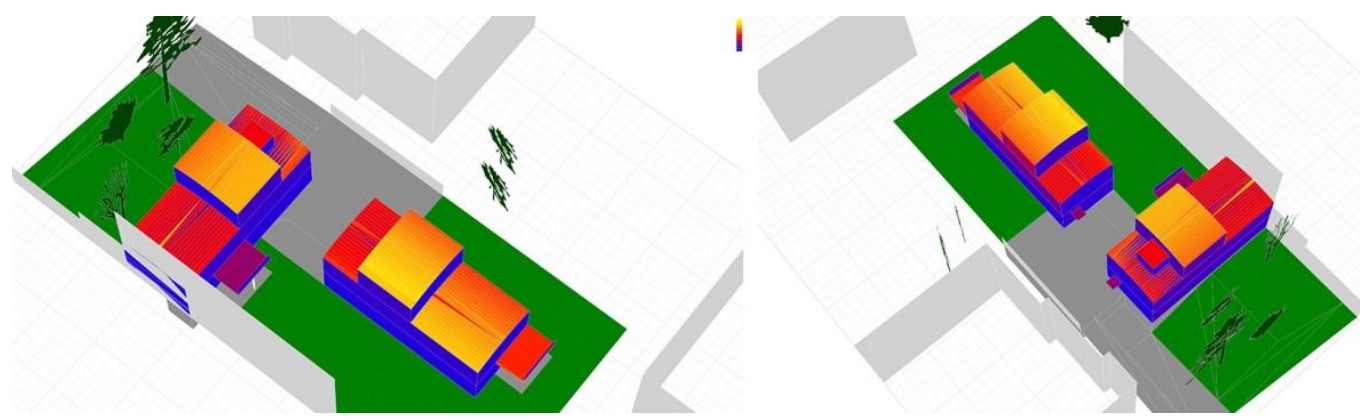

3. Nivel de radiación recibido por cada una de las superficies que componen la envolvente de las viviendas.

Debido a los edificios y árboles que se sitúan en el entorno de la parcela, especialmente al edificio colindante, las viviendas reciben un nivel de radiación bajo. Especialmente la vivienda A, paralela a la rue de Longchamp.

Del estudio se desprende que las dos viviendas deberían tener un comportamiento higrotérmico muy parecido ya que aunque tienen orientaciones opuestas, las condiciones del entorno y su volumetría hacen que la radiación recibida a lo largo del año sea muy parecida. En todo caso la vivienda $\mathrm{B}$, recibe un poco más de asoleamiento 
por lo que podría alcanzar mayores grados de confort, aunque al tener mayor superficie en contacto con el exterior $^{31}$ las pérdidas también son mayores.

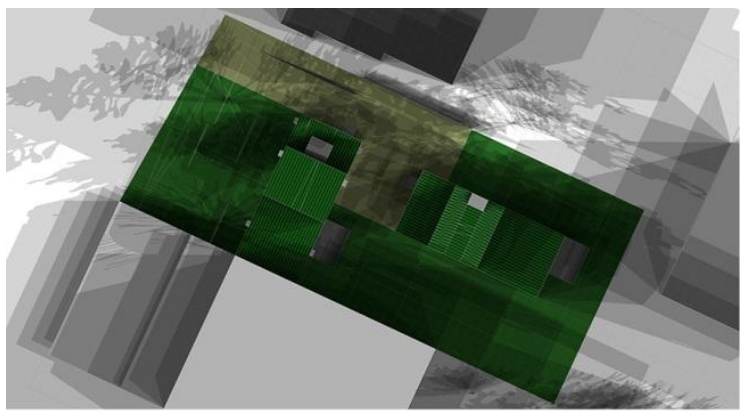

21 de Junio

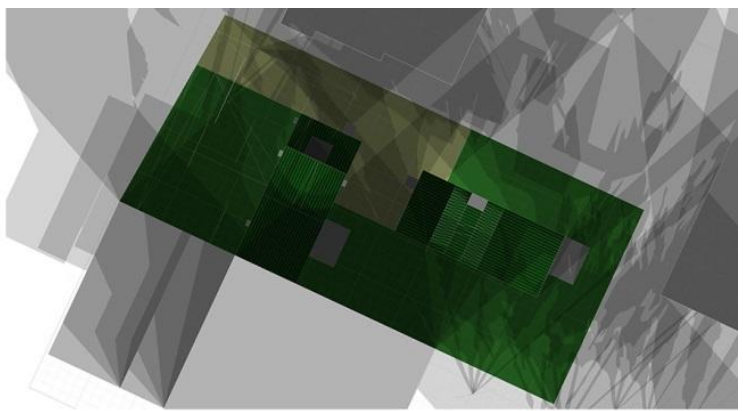

21 de Septiembre

4. Estudio de rango de sombras para los solsticios. 21 de Junio - 21 de Septiembre. Planta.
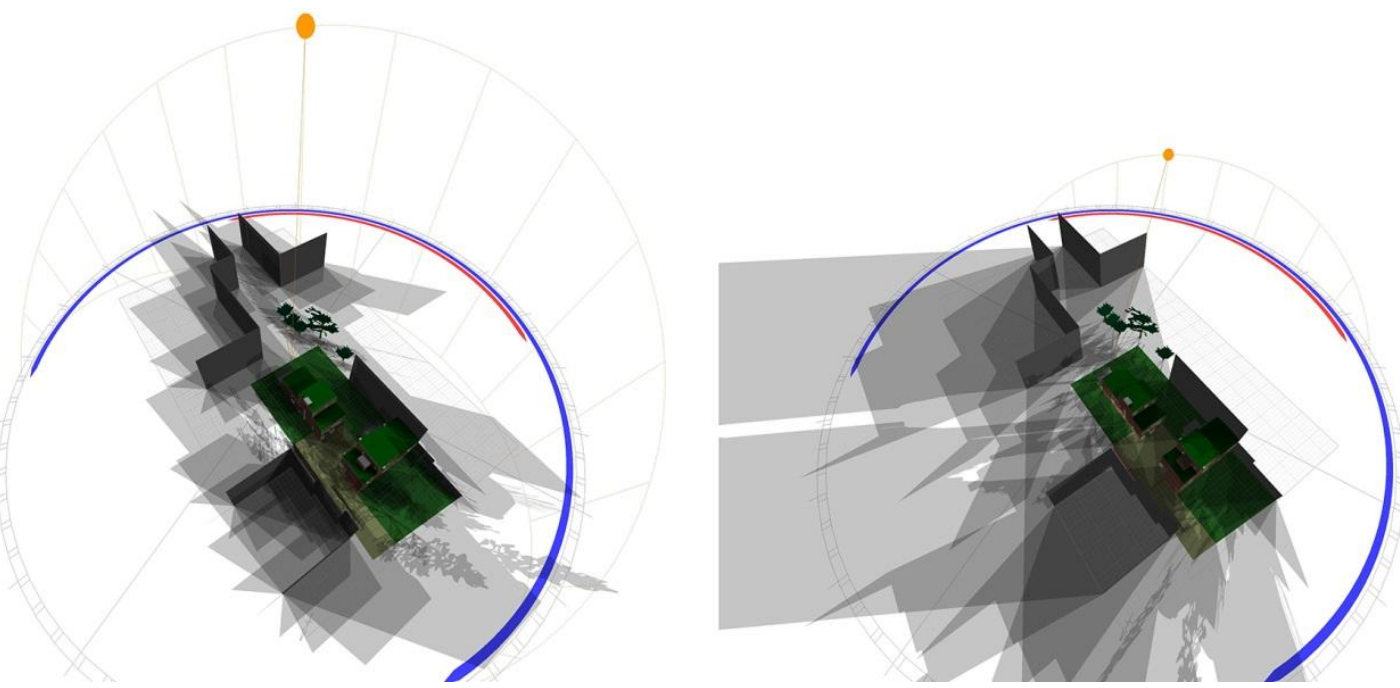

5. Estudio de rango de sombras para los solsticios. 21 de Junio - 21 de Diciembre. Vista aérea.
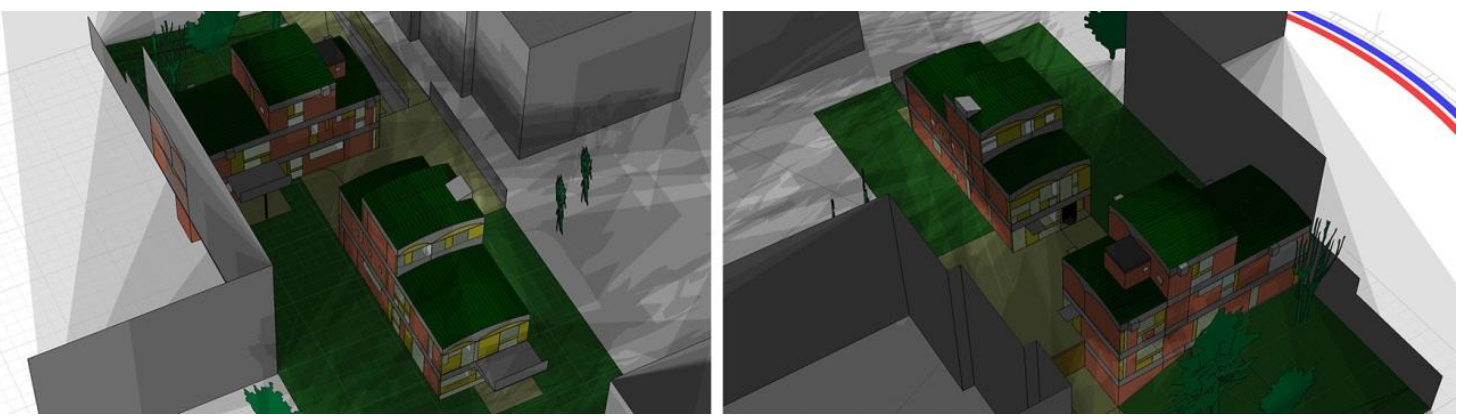

6. Estudio rango de sombras. 21 de Diciembre. Solsticio de invierno.

\footnotetext{
${ }^{31}$ La vivienda A tiene un testero en contacto con el edificio contiguo en el que ni si quiera se dobló el cerramiento. El espacio interior de la vivienda está directamente en contacto con la medianera sobre la que se aplicó el revestimiento interior.
} 

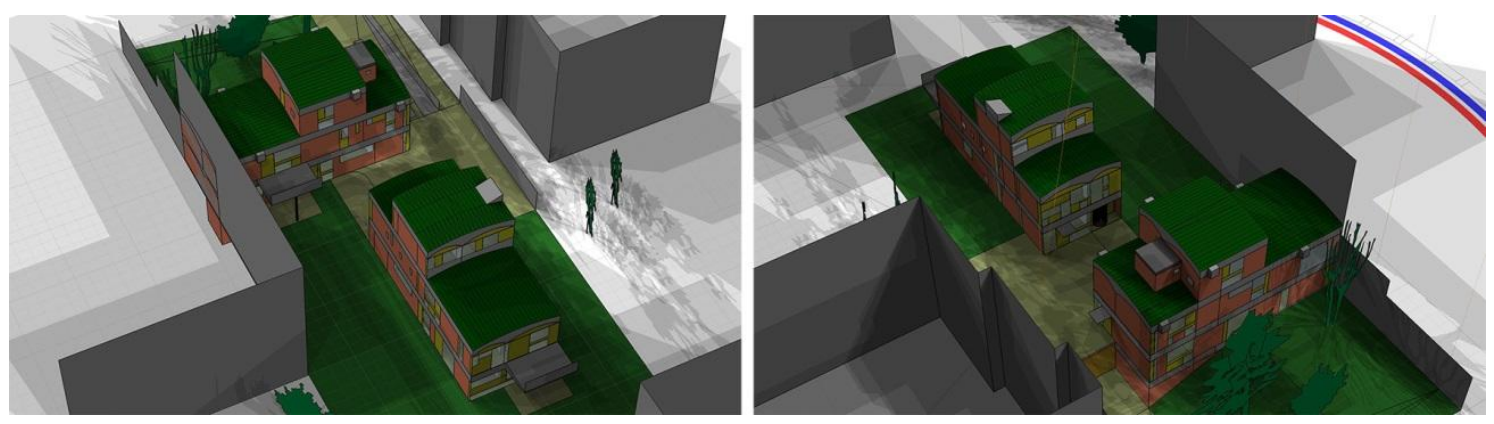

7. Estudio rango de sombras. 21 de Junio. Solsticio de verano.

\subsection{Envolvente}

Durante el periodo en el que se hicieron las mediciones higrotérmicas, adicionalmente se realizó un estudio fotográfico de las fachadas y del interior de las viviendas, así como toma de medidas, que ha permitido realizar un levantamiento planimétrico del estado actual de las mismas.

VIVENDA A

\begin{tabular}{|c|c|c|c|c|c|c|c|c|c|c|c|c|c|c|}
\hline \multirow[b]{3}{*}{$\frac{\dot{\bar{z}}}{\overline{\bar{z}}}$} & \multicolumn{3}{|c|}{ CERRAM. MACIZO } & \multicolumn{4}{|c|}{ CUATRIÈME MUR } & & & & & & & \\
\hline & \multirow[b]{2}{*}{ 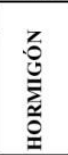 } & \multirow[b]{2}{*}{ 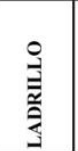 } & \multirow[b]{2}{*}{ 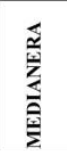 } & \multicolumn{2}{|c|}{ MADERA } & \multirow{2}{*}{ 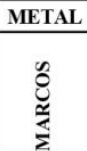 } & \multirow[b]{2}{*}{ 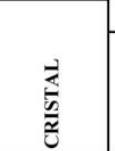 } & \multirow[b]{2}{*}{ 氙 } & \multirow[b]{2}{*}{$\begin{array}{l}\frac{1}{1} \\
0 \\
0 \\
0 \\
0 \\
0\end{array}$} & \multirow[b]{2}{*}{ 总 } & \multirow[b]{2}{*}{$\begin{array}{l}1 \\
\vdots \\
\vdots \\
0 \\
0 \\
0\end{array}$} & \multirow[b]{2}{*}{ 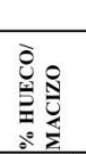 } & \multirow[b]{2}{*}{ 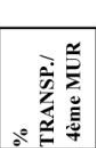 } & \multirow[b]{2}{*}{ 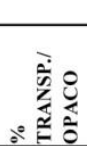 } \\
\hline & & & & 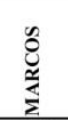 & 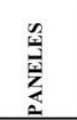 & & & & & & & & & \\
\hline SUR & 4,50 & 13,90 & 43,45 & 0,17 & 0,80 & 0,04 & 0,16 & 63,02 & $18,51 \%$ & 1,17 & $1,60 \%$ & $1,86 \%$ & $13,68 \%$ & $0,25 \%$ \\
\hline ESTE & 27,60 & 48,04 & 0,00 & 4,49 & 10,97 & 1,34 & 16,72 & 109,16 & $32,07 \%$ & 33,52 & $45,84 \%$ & $30,71 \%$ & $49,88 \%$ & $18,09 \%$ \\
\hline & & & & & & & TOTALES & 340,42 & $100,00 \%$ & 73,12 & $100,00 \%$ & & & \\
\hline
\end{tabular}
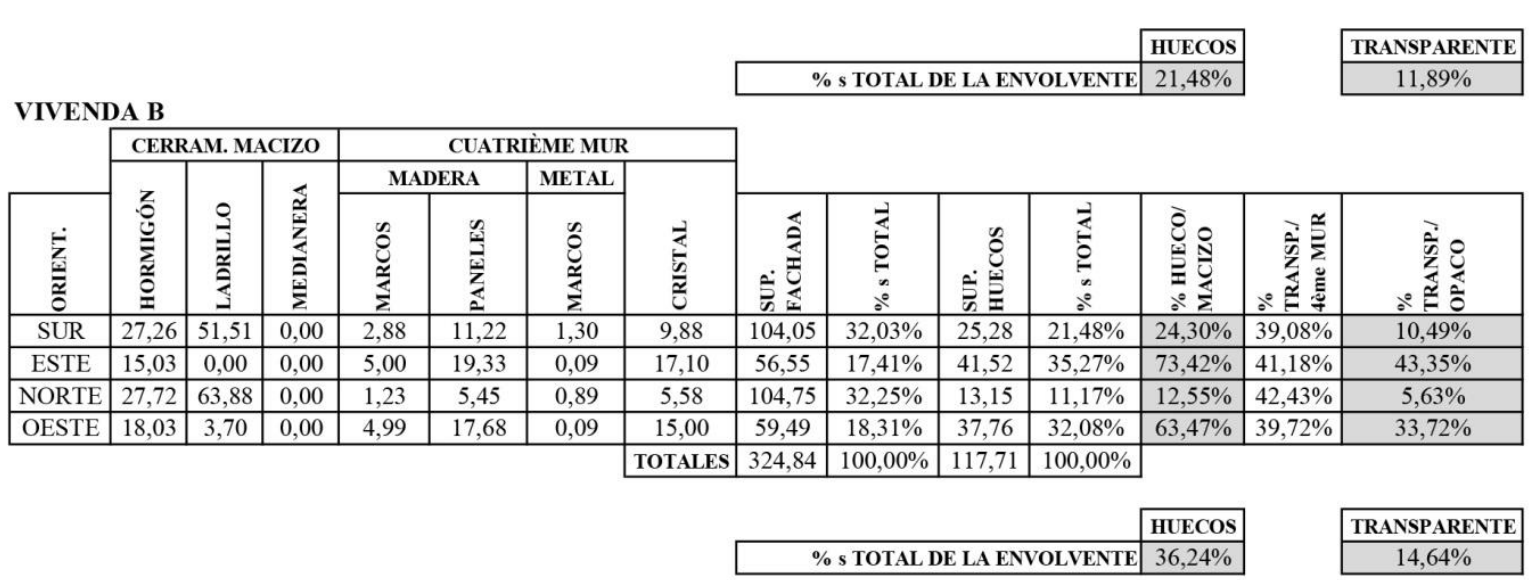

Todos los datos en $\mathrm{m}^{2} \mathrm{y}$ porcentajes

8. Tabla estudio comparativo de la envolvente.

En base a esta información se realiza un estudio comparativo de la envolvente que nos permite observar que la vivienda A tiene un porcentaje global de huecos de 21,48\% y de zona transparente de $11,89 \%$ que son menores que los de la vivienda B, $36,24 \%$ y $14,64 \%$, respectivamente. Por tanto dentro de la envolvente el porcentaje que ocupa el muro de ladrillo de doble hoja -mucho más aislante que los huecos-es mayor y por tanto el coeficiente global de la vivienda también. Este hecho es contraproducente para la adquisición de ganancias solares pero, como ya hemos visto, la incidencia solar en las viviendas es baja y por tanto prevalece el hecho de mantener las ganacias internas. 
La fachada Sur, que es la orientación más favorable para la latitud de París, en la vivienda A tiene una incidencia mínima puesto que gran parte de ella está en contacto con un espacio interior y en la vivienda B recibe muy poca radiación solar debido a la obstrucción del edificio colindante. Además el porcentaje de trasparencia ${ }^{32}$, de $10,49 \%$, es bastante bajo y tampoco permite un gran acceso de rayos solares.

Con respecto a las fachadas Este y Oeste, que tienen más acceso solar por la mañana y la tarde; en la vivienda B están resueltas prácticamente como un gran hueco que se cierra con el cuatrième mur, pero al ser las fachadas estrechas, su incidencia sobre el global de la envolvente es pequeña, alrededor del $18 \%$ cada una de ellas. Además la fachada Oeste de esta vivienda queda bloqueda completamente por la otra para la incidencia solar de invierno. En la vivienda A estas dos fachadas suponen el 32\% cada una de ellas y aunque también se produce una obstrucción parcial, el porcentaje de transparencia es mayor, estando resuelta la parte maciza con muro de ladrillo de doble hoja y cámara.

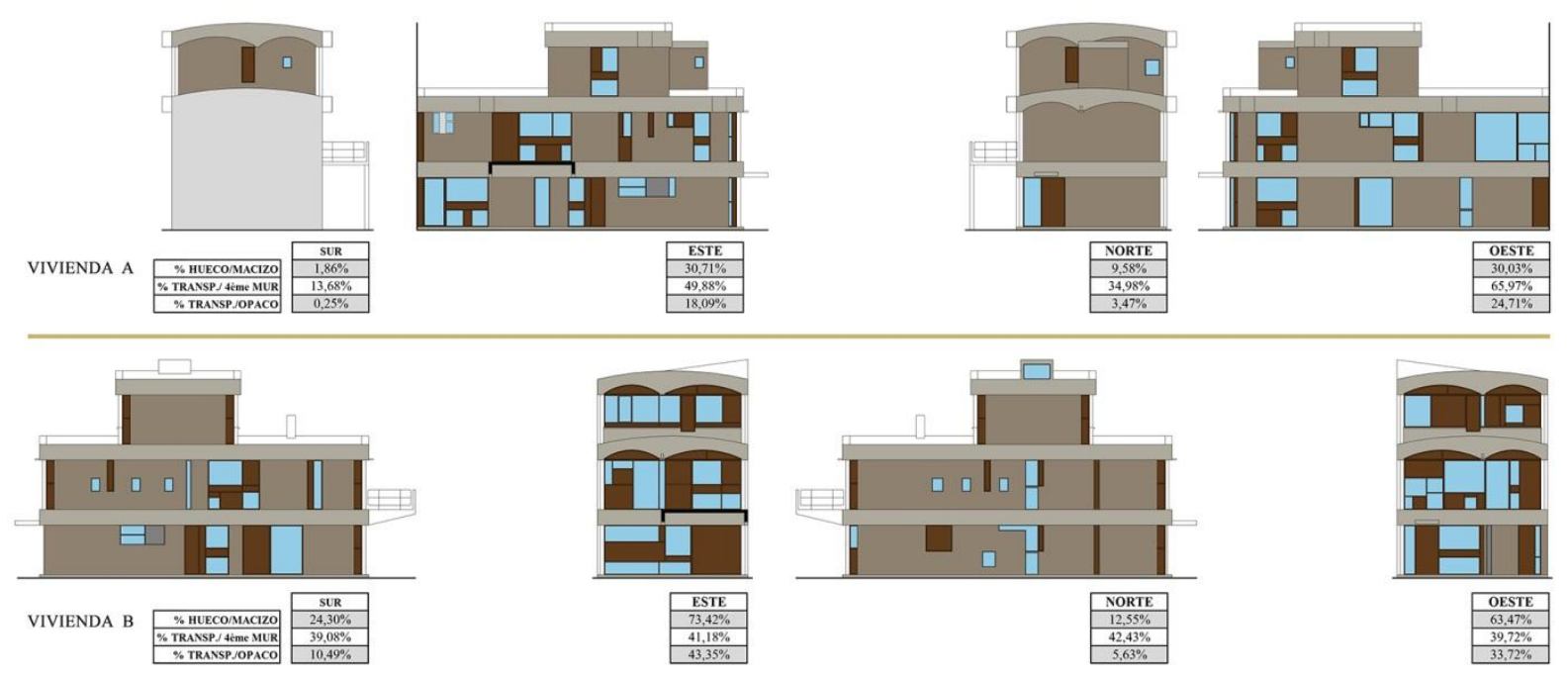

9. Estudio comparativo de la envolvente. Alzados.

En conclusión queda patente que a pesar de que la vivienda B tiene una orientación más favorable, las condiciones de controno y el diseño de huecos de las envolventes hacen que la balanza se incline hacia un mejor diseño de la vivienda A. Con el estudio in situ comporbaremos si este hecho se produce en la realidad.

\section{Estudio empírico}

Durante los días 15, 16,17 y 18 de Enero de 2015, se realizó una campaña de toma de datos en las Maisons Jaoul. Para ello se utilizaron dos medidores Whöler 210 que registran y almacenan medidas de temperatura, humedad relativa y concentración de $\mathrm{CO}_{2}$ según intervalos indicados en su configuración.

Las herramientas se colocaron en las estancias principales de las viviendas en la planta baja, cerca de cerramientos opacos que dan al patio que se genera entre las dos viviendas. Debido al efecto de estabilización de los aparatos de medición se descartan las primeras 3 horas, de manera que en los gráficos que se recogen a continuación se representan las mediciones a partir de las 20:00 h del día 15 de Enero hasta las 20:00 h del día

\footnotetext{
${ }^{32}$ Para el cálculo de este valor se ha tomado el $100 \%$ de las contraventanas que existen abiertas permitiendo la mayor incidencia solar.
} 
18 de Enero. Los datos de temperatura y humedad exteriores se han obtenido de la web http://www.meteofrance.com/ descargando la información pública de los días en los que se realizó la medición.

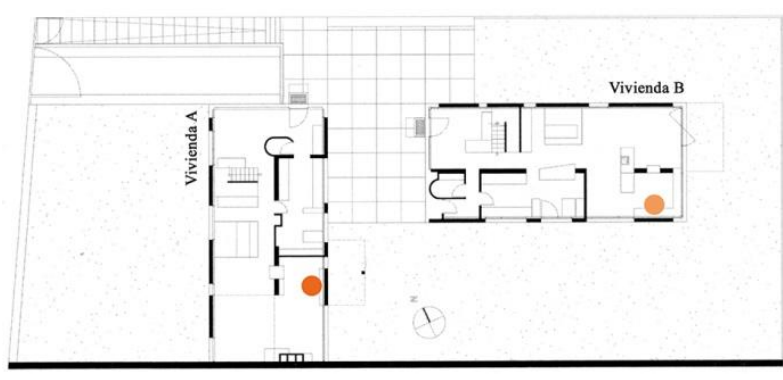

10. Plano de las viviendas con la situación de las herramientas de medición.

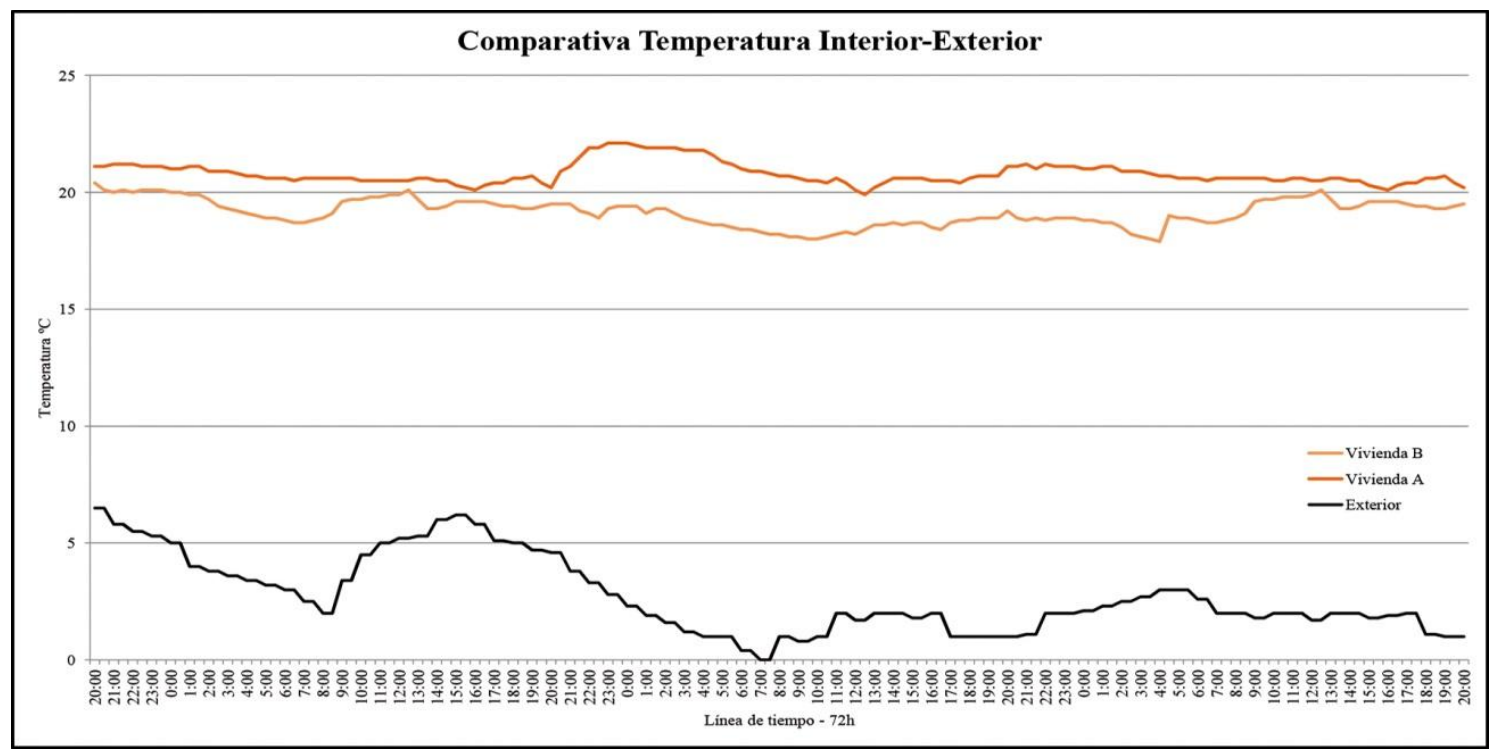

11. Gráfico comparativo. Temperatura interior de las viviendas y Temperatura exterior.

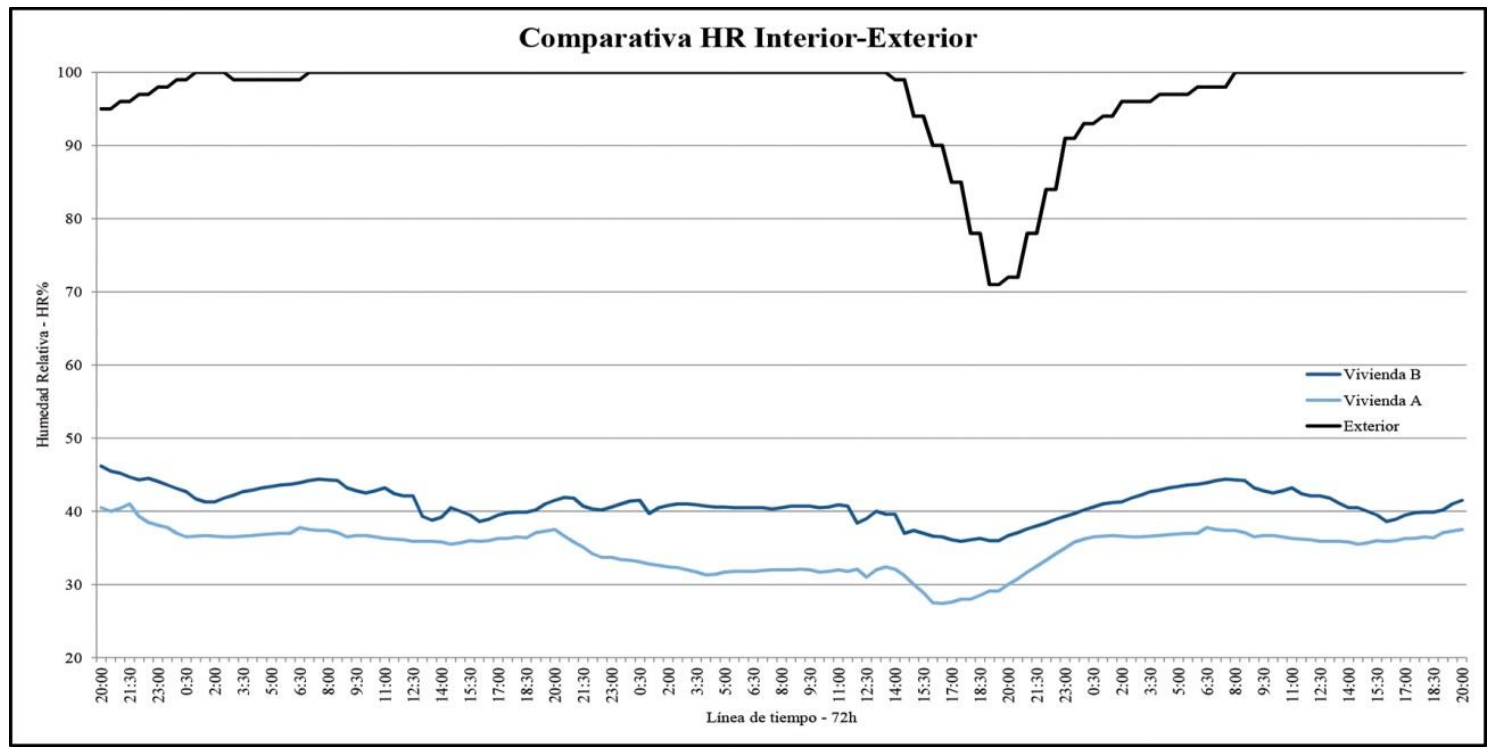

12. Gráfico comparativo. Humedad Relativa interior de las viviendas y Humedad Relativa exterior. 


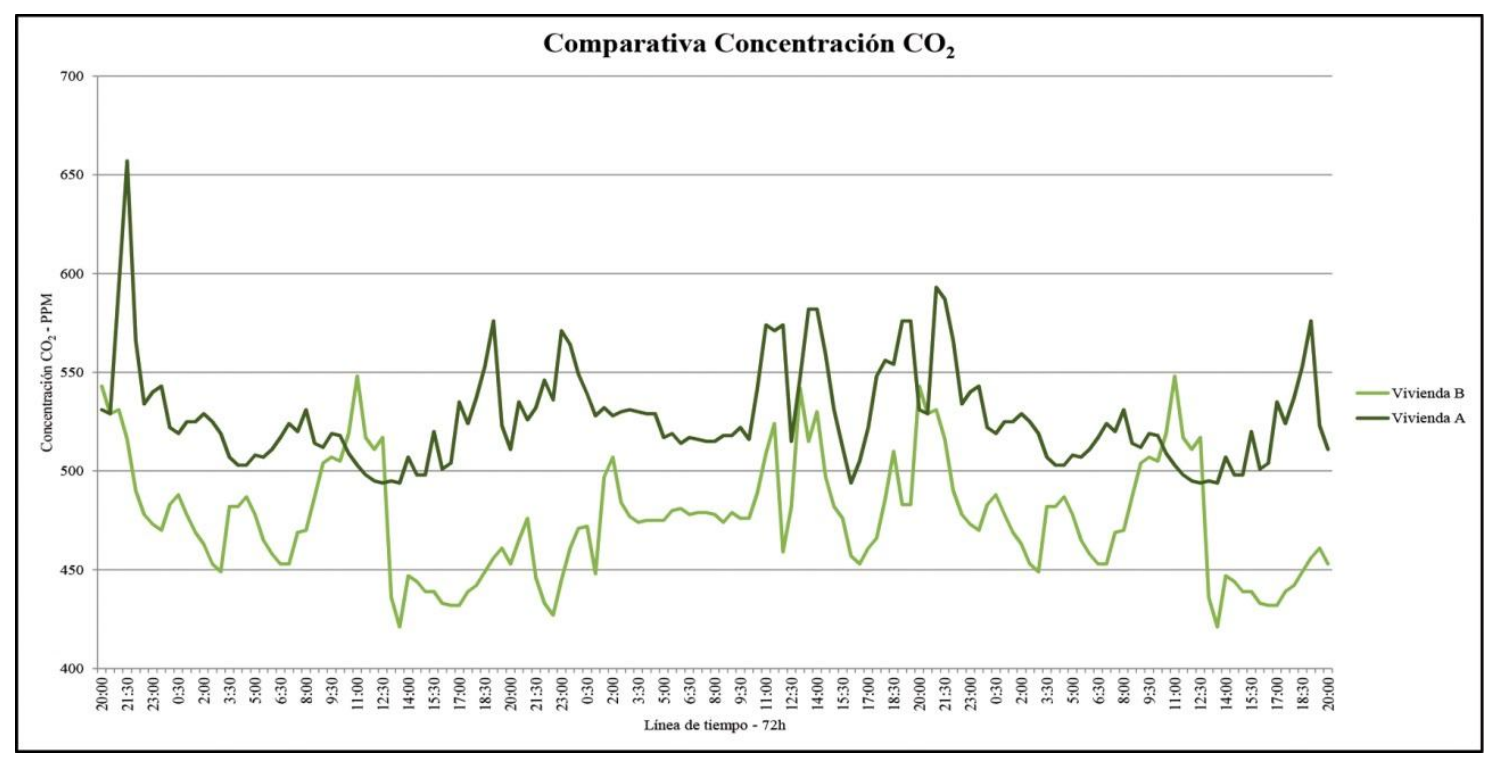

13. Gráfico comparativo. Concentración de $\mathrm{CO} 2$ en el interior de las viviendas.

De los datos extraídos, se pueden extraer varias conclusiones sobre el comportamiento higrotérmico de las viviendas, pero lo más destacable en realidad es comprobar que se produce una diferencia de temperatura y humedad entre la vivienda A y la B. Esta última es en todo el periodo estudiado más fría y húmeda. En los siguientes gráficos analizamos en detalle esa diferencia.
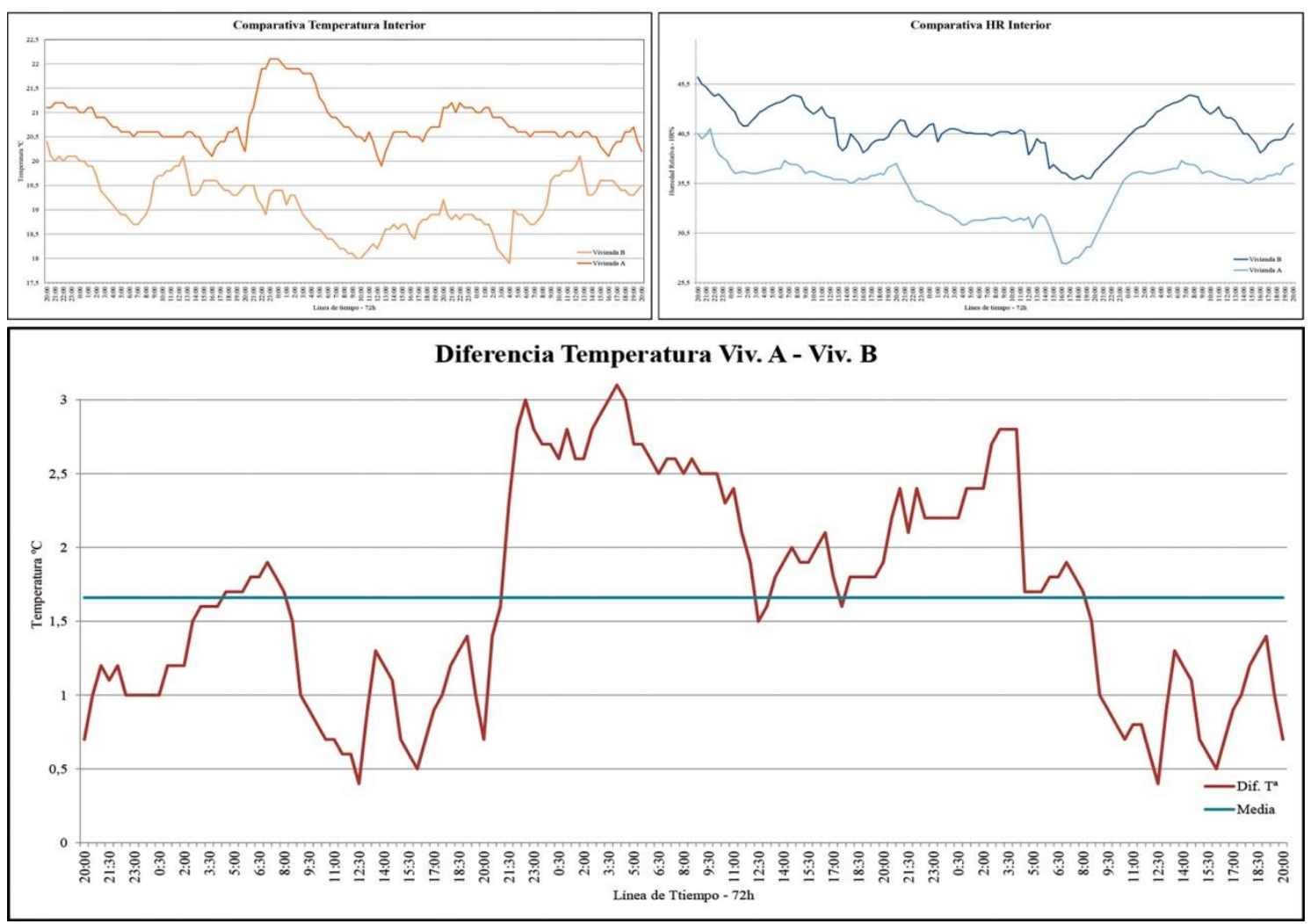

14. Gráfico comparativo. Diferencia de Temperatura y Humedad Relativa. Variación de la diferencia de Temperatura y Media 
La diferencia de Temperatura oscila entre $00^{\prime}{ }^{\circ} \mathrm{C}$ y $3{ }^{\prime} 1{ }^{\circ} \mathrm{C}$. Por un lado, las diferencias son menores cuando la incidencia solar es mayor, entre las 12:30 h y las 17:00 h. Este hecho se repite los tres días a pesar de las diferencias térmicas existentes entre ellos. Por el contrario, por las noches y las horas en las que no hay incidencia solar, la diferencia se acentúa hasta llegar al máximo justo antes del amanecer, aproximadamente sobre las 5:00 h.

La diferencia media de Temperaturas es de $1^{\prime} 66^{\circ} \mathrm{C}$ tal y como se indica en el gráfico anterior ${ }^{33}$, y parece que habitualmente es así, puesto que los días en los que se han realizado las mediciones los datos climatológicos han estado muy cerca de la media habitual para la época en París.

Respecto a la Humedad Relativa, la vivienda B tiene registros de humedad entre un 2'7 \% y 9'4 \% superiores a la vivienda A. No son diferencias muy altas, ya que la media se coloca en 6' $1 \%$, pero tal y como veremos más adelante es suficiente como para ser percibido por los ocupantes.

\section{Estudio subjetivo}

Las Maisons Jaoul fueron adquiridas en 2010 por dos hermanas que querían vivir en la zona, que siempre habían vivido juntas y que querían seguir haciéndolo. De este modo estas viviendas unifamiliares, independientes pero que comparten solar, situación completamente característica, cumplían con sus necesidades.

Ambas familias, tanto las hermanas como sus respectivos maridos, nunca han tenido un conocimiento muy profundo de la Historia de la Arquitectura, ni tienen una sensación especial de habitar lo que muchos arquitectos denominaríamos como un tesoro de la Arquitectura del s. XX. Paradójicamente, esta situación hace que su opinión sobre las viviendas no esté mediatizada ni sesgada por una componente podríamos decir ideológica y por tanto se muestra como altamente reveladora.

Tras una larga conversación con Philippe Chevalier - propietario de la vivienda A- y habiendo realizado preguntas a los hijos de las dos familias, se extrae las siguientes conclusiones: Todos ellos perciben que la vivienda A es la más confortable de las dos tanto en inverno como en verano. En general encuentran las casas un poco frías, algo por otro lado lógico debido a las obstrucciones solares existentes, pero especialmente la vivienda B, destacando que es además mucho más húmeda. En general están contentos con las viviendas, especialmente con la posibilidad de pasar de una a otra por el sótano y encuentran los espacios confortables y agradables aunque poco luminosos en algunas épocas del año.

\section{Conclusiones}

Tal y como reflejan los datos del estudio empírico y con el refuerzo de la percepción de los habitantes, el comportamiento higrotérmico de las Maisons Jaoul funciona tal como se podría esperar.

El estudio numérico nos permite deducir que son casas en general algo frías y en las que es difícil la obtención de ganancias solares debido a las condiciones de contorno. Por otro lado la inercia de sus muros permite que los aportes de calor del sistema de calefacción se aprovechen de manera adecuada, especialmente en la vivienda A.

\footnotetext{
${ }^{33}$ La moda en este caso es de valor $1^{\circ} \mathrm{C}$, es decir es la situación que más se repite. Pero debido a que la variación entre unos momentos y otros no es exagerada, la media representa bien la sensación térmica entre las dos viviendas.
} 
Cabía esperar que la vivienda B tuviera un comportamiento algo peor y finalmente ha resultado ser así. En cualquier caso, sería necesario hacer un estudio completo de las viviendas en el periodo estival también y de las instalaciones de calefacción para comprender la diferencia de temperatura y humedad que se han constatado en este estudio.

A pesar de todo ello, las dos familias que actualmente habitan las viviendas han hecho de sus espacios sus coquilles de l'escargot en las que disfrutan de confort, intimidad y protección. Revelando que las Maisons Jaoul siguen siendo unas viviendas con una condición excepcional de la obra de Le Corbusier.

\section{Imágenes}

1. Esquema de ventilaciones cruzadas establecidas exclusivamente mediante aerateurs

2. Gráfico comparativo. Radiación Solar Directa y Difusa en las dos viviendas.

3. Nivel de radiación recibido por cada una de las superficies que componen la envolvente de las viviendas.

4. Estudio de rango de sombras para los solsticios. 21 de Junio - 21 de Septiembre. Planta.

5. Estudio de rango de sombras para los solsticios. 21 de Junio - 21 de Diciembre. Vista aérea.

6. Estudio rango de sombras. 21 de Diciembre. Solsticio de invierno.

7. Estudio rango de sombras. 21 de Junio. Solsticio de verano.

8. Tabla estudio comparativo de la envolvente.

9. Estudio comparativo de la envolvente. Alzados

10. Plano de las viviendas con la situación de las herramientas de medición.

11. Gráfico comparativo. Temperatura interior de las viviendas y Temperatura exterior.

12. Gráfico comparativo. Humedad Relativa interior de las viviendas y Humedad Relativa exterior.

13. Gráfico comparativo. Concentración de $\mathrm{CO} 2$ en el interior de las viviendas

14. Gráfico comparativo. Diferencia de Temperatura y Humedad Relativa. Variación de la diferencia de Temperatura y Media

NOTA: Todas las imágenes elaboradas por el autor.

\section{Bibliografía}

Banham, Reyner: Le Corbusier: "A critique of his work", The Architectural Review. Octubre 1966, n 834. pp. 97-108.

Benton, Tim: "La Villa Baizeau et le brise-soleil", A.A.V.V. Le Corbusier et la Mediterranée. Marseille : Editions Parenthèses, 1987.

Bill, Max (Pub.); Le Corbusier: Le Corbusier. Oeuvre complète 1934-38. Zurich: Les Éditions d'Architecture, 1973.

Boesiger, Willy (Ed.) ; Le Corbusier ; Stonorov, O: Le Corbusier et Pierre Jeanneret. Oeuvre complète 1910-29. Zurich: Les Éditions d'Architecture, 1973.

Boesiger, Willy; Le Corbusier: Le Corbusier. Oeuvre complète 1938-46. Zurich: Les Éditions d'Architecture, 1973.

Boesiguer, Willy; Girsberger, G.: Le Corbusier 1910-1965, Barcelona, Editorial Gustavo Gili, 1971.

Frampton, Keneth: Le Corbusier. Turín, Ediciones Hazan, 1997 
Gómez Sierra, Carlos M.: "Le Corbusier y la casa Curruchet. Una aproximación teórica desde la problemática del clima", Área digital. "Área historia. Utopía y ciudad". Febrero 2002 n² 2. Chaco, Argentina. Facultad de Arquitectura y Urbanismo.

Le Corbusier, L'Almanach d'Architecture moderne (Paris: Crès, 1926; Paris: Connivence, 1975)

Le Corbusier: "Théorie du toit-jardin", en L’Architecture vivante, Otoño-Invierno, 1927. Paris: Jean Badovici.

Le Corbusier: Vers une architecture. Paris: Vincent, Freal and Cie., 1958.

Maniaque Benton, Caroline: Le Corbusier and the Maisons Jaoul. New York: Princeton Architectural Press, 2009.

Menin, Sarah; Samuel, Flora: Nature and Space, Aalto and Le Corbusier. Londres, Ed. Route Ledge, 2003.

Serra, Rafael Serra: Arquitectura y Climas. Barcelona, Gustavo Gili, 1999.

Siret, Daniel ; Harzallah, Amina: Architecture et côntrole de l'ensoleillment. Conferencia, manuscrito publicado en "Congrès IBPSA France", Ecole national Supérieure d'Architecture de Nantes, France 2006.

Stirling, James: "De Garches a Jaoul. Le Corbusier como arquitecto doméstico en 1927 y 1953". Anales de Arquitectura. 1993, $\mathrm{n}^{\circ}$ 5. Valladolid: Universidad de Valladolid. pp. 209-213. Artículo recogido y traducido, original: "From Garches to Jaoul: Le Corbusier as Domestic Architect in 1927 and 1953". The Architectural Review. Agosto 1955, $\mathrm{n}^{\circ} 118$.

Torres Cueco, Jorge: Le Corbusier: Visiones de la técnica en 5 tiempo. Barcelona: Colección Arquithemas, 2004. 